\title{
Epidemiology and outcomes of Clostridium difficile infection in allogeneic hematopoietic cell and lung transplant recipients
}

\author{
E.R. Dubberke ${ }^{1}$ (D) | K.A. Reske ${ }^{1}$ (D) | M.A. Olsen ${ }^{1}$ \\ K. Bommarito ${ }^{1}$ \\ A.A. Cleveland ${ }^{2}$ \\ F.P. Silveira ${ }^{3}$ \\ M.G. Schuster ${ }^{4}$ \\ C.A. Kauffman ${ }^{5}$ \\ R.K. Avery ${ }^{6}$ \\ P.G. Pappas ${ }^{7}$
}

T.M. Chiller ${ }^{2}$

\author{
${ }^{1}$ Division of Infectious Diseases, Washington \\ University School of Medicine, St. Louis, \\ MO, USA \\ ${ }^{2}$ Centers for Disease Control and \\ Prevention, Atlanta, GA, USA \\ ${ }^{3}$ Division of Infectious Diseases, University \\ of Pittsburgh, Pittsburgh, PA, USA \\ ${ }^{4}$ University of Pennsylvania, Philadelphia, \\ PA, USA \\ ${ }^{5}$ VA Ann Arbor Healthcare \\ System, University of Michigan Medical \\ School, Ann Arbor, MI, USA \\ ${ }^{6}$ Johns Hopkins University, Baltimore, MD, \\ USA \\ ${ }^{7}$ University of Alabama at Birmingham, \\ Birmingham, AL, USA

\section{Correspondence} \\ Erik R. Dubberke, Washington University \\ School of Medicine, St. Louis, MO, USA. \\ Email: edubberk@wustl.edu \\ Funding information \\ National Institutes of Health, Grant/Award \\ Number: K23AI065806; Centers for Disease \\ Control and Prevention, Grant/Award \\ Number: U01CK000134
}

\begin{abstract}
Background: Clostridium difficile infection (CDI) is a common complication of lung and allogeneic hematopoietic cell (HCT) transplant, but the epidemiology and outcomes of CDI after transplant are poorly described.

Methods: We performed a prospective, multicenter study of CDI within 365 days post-allogeneic HCT or lung transplantation. Data were collected via patient interviews and medical chart review. Participants were followed weekly in the 12 weeks post-transplant and while hospitalized and contacted monthly up to 18 months post-transplantation.

Results: Six sites participated in the study with 614 total participants; 4 enrolled allogeneic HCT (385 participants) and 5 enrolled lung transplant recipients (229 participants). One hundred and fifty CDI cases occurred within 1 year of transplantation; the incidence among lung transplant recipients was $13.1 \%$ and among allogeneic HCTs was $31.2 \%$. Median time to CDI was significantly shorter among allogeneic HCT than lung transplant recipients (27 days vs 90 days; $P=.037$ ). CDI was associated with significantly higher mortality from 31 to 180 days post-index date among the allogeneic $\mathrm{HCT}$ recipients (Hazard ratio $[\mathrm{HR}]=1.80 ; P=.007$ ). There was a trend towards increased mortality among lung transplant recipients from 120 to 180 days post-index date (HR = 4.7, $P=.09)$.

Conclusions: The epidemiology and outcomes of CDI vary by transplant population; surveillance for CDI should continue beyond the immediate post-transplant period.
\end{abstract}

KEYWORDS

Clostridium difficile, epidemiology, hematopoetic cell transplant, lung transplant, outcomes

\section{1 | INTRODUCTION}

Clostridium difficile infection (CDI) is the most common infectious cause of healthcare-associated diarrhea, and risk factors for CDI include antibiotic use, high severity of illness, hospitalization, and immunosuppression. ${ }^{1-4}$ Solid organ and hematopoetic cell transplant (HCT) recipients are particularly vulnerable to CDI. ${ }^{5}$ The incidence of $\mathrm{CDI}$ among allogeneic $\mathrm{HCT}$ recipients is high, with an upper estimate of about $30 \% .{ }^{6-14}$ Among solid organ transplant recipients, those receiving a lung transplant are at increased risk of CDI, with incidence estimates up to $10.8 \% .{ }^{15,16}$ There are few data available on the association between transplantation, $\mathrm{CDI}$, and morbidity and mortality. In one study lung transplant recipients had greater risk of fulminant colitis compared to non-transplant patients, ${ }^{15}$ and CDI has been associated with increased mortality, particularly during the early post-transplant period. ${ }^{16,17}$ In allogeneic HCT recipients, 
the impact of CDI on mortality is unclear. CDI was associated with significantly higher mortality within 180 days of infection in 2 studies, ${ }^{8,18}$ but Willems et $\mathrm{al}^{14}$ found no difference in overall survival between CDI cases and controls within 2 years of transplantation. Additionally, variations in study design make it difficult to draw firm conclusions about the morbidity and mortality associated with CDI after allogeneic HCT and lung transplantation. A better understanding of the epidemiology and outcomes of CDI among allogeneic HCT and lung transplant recipients would help clinicians treat patients appropriately and help guide infection prevention priorities.

The purpose of this study was to describe and compare the incidence and outcomes of CDI after allogeneic HCT and lung transplantation, using a multicenter, prospective study design. This study was performed in conjunction with the Organ Transplant Infection Prevention and Detection Project (OTIP) of the Centers for Disease Control and Prevention (CDC). OTIP was a prospective cohort study of all proven and probable invasive fungal infections in patients undergoing allogeneic HCT or lung transplantation (lung and allogeneic HCT transplants were selected for analysis because of the higher rates of invasive infections among these patients); however, data on other infections, including CDI, were collected as well, providing a prospective opportunity to study $\mathrm{CDI}$ after lung and allogeneic $\mathrm{HCT}$ transplant.

\section{2 | PATIENTS AND METHODS}

Six academic medical centers from across the United States participated in the OTIP study. Lung transplant recipients were enrolled at 5 sites, and allogeneic HCT recipients were enrolled at 4 sites, from April 2007 to March 2010. Study participants were enrolled during their transplant hospitalization. All participants provided written informed consent. Each institution's institutional review board (IRB) approved the study.

\section{1 | Data collection}

Participants underwent clinical assessments at enrollment and weekly during their transplant hospitalization. After discharge, participants were contacted by phone weekly up to 12 weeks posttransplant. After 12 weeks, participants were contacted monthly. If readmitted to the hospital, participants were followed weekly until discharge. Participants were followed up for 2.5 years posttransplant for readmissions, infections, and other outcomes.

Demographic data collected at enrollment included age, sex, race, underlying disease status, comorbid disease, type of transplant conditioning, prior chemotherapy/immunosuppressive therapies, and transplantation history. Other data collected at enrollment included transplant date, donor/recipient CMV status, immunosuppressive medications, and laboratory culture and/or test results, including $C$. difficile test results. The OTIP sites used a variety of CDI diagnostic methods during the study period: EIA for toxins A/B (sites $B, D$, and F), cytotoxicity assay (site A), antigen detection or PCR (site C), and GDH plus toxin A/B immunoassay (site E). The weekly inpatient and outpatient assessments included patient status (home, inpatient, ICU, deceased), mechanical ventilation, current medications, and symptoms of infection. All infections were reviewed by Infectious Diseases physicians at each site to determine whether the infection was probable, confirmed, or neither. Infections were defined according to National Nosocomial Infections Surveillance (NNIS) criteria. ${ }^{19}$ In addition to patient interviews, clinical data were collected prospectively from medical records when participants were hospitalized and as available from outpatient clinic records. In order to be considered a CDI case, a patient was required to have a positive laboratory test for $C$. difficile and meet the NNIS criteria for gastroenteritis and/or GI tract infection in the clinical judgment of the Infectious Disease physician.

\section{2 | Data analyses}

Clostridium difficile infection cases were included if they occurred any time within 365 days post-transplant. The date of first positive laboratory test for $C$. difficile was used as the index date for analyses. For individuals without CDI, an analogous "index" date was randomly selected such that the distribution of time from transplant to index date was comparable between CDI cases and controls. For patients with $>1$ transplant during the study period, only the first transplant was included, and patients were censored at the time of second transplant. For this analysis, patients were excluded if they were enrolled $>7$ days post-transplant; prospective data on these patients' pre- and peri-transplant medications were limited. Patients also were excluded if they had CDI at the time of transplant. There were 787 patients at the 6 sites enrolled in OTIP; 614 (86\%) met all inclusion criteria for this study and were included in analyses (Figure 1).

Because the primary outcome of interest in the OTIP study was fungal infections, not CDI, limited data on antimicrobial use were available. Thus, analyses focused on demographics and outcomes among CDI cases and controls, as well as the general epidemiology of CDI among the lung and allogeneic HCT populations. Chisquare and logistic regression were used for univariate analyses of categorical variables, as appropriate. Kaplan-Meier plots and Cox proportional hazards models with heavy-side functions were used to compare survival between $\mathrm{CDI}$ cases and controls up to 180 days post-index date. A $P$-value of .05 was considered significant in all analyses. Analyses were performed with SPSS, version 23.0 (Armonk, NY, USA), SAS version 9.2 (Cary, NC, USA), and Stata MP11 (College Station, TX, USA).

\section{3 | RESULTS}

A total of 614 patients met inclusion criteria for this study and were included in analyses. Lung transplant recipients accounted for $37 \%$ of the enrolled patients $(N=229)$ and allogeneic $\mathrm{HCT}$ recipients accounted for $63 \%(N=385)$. One hundred and fifty patients 


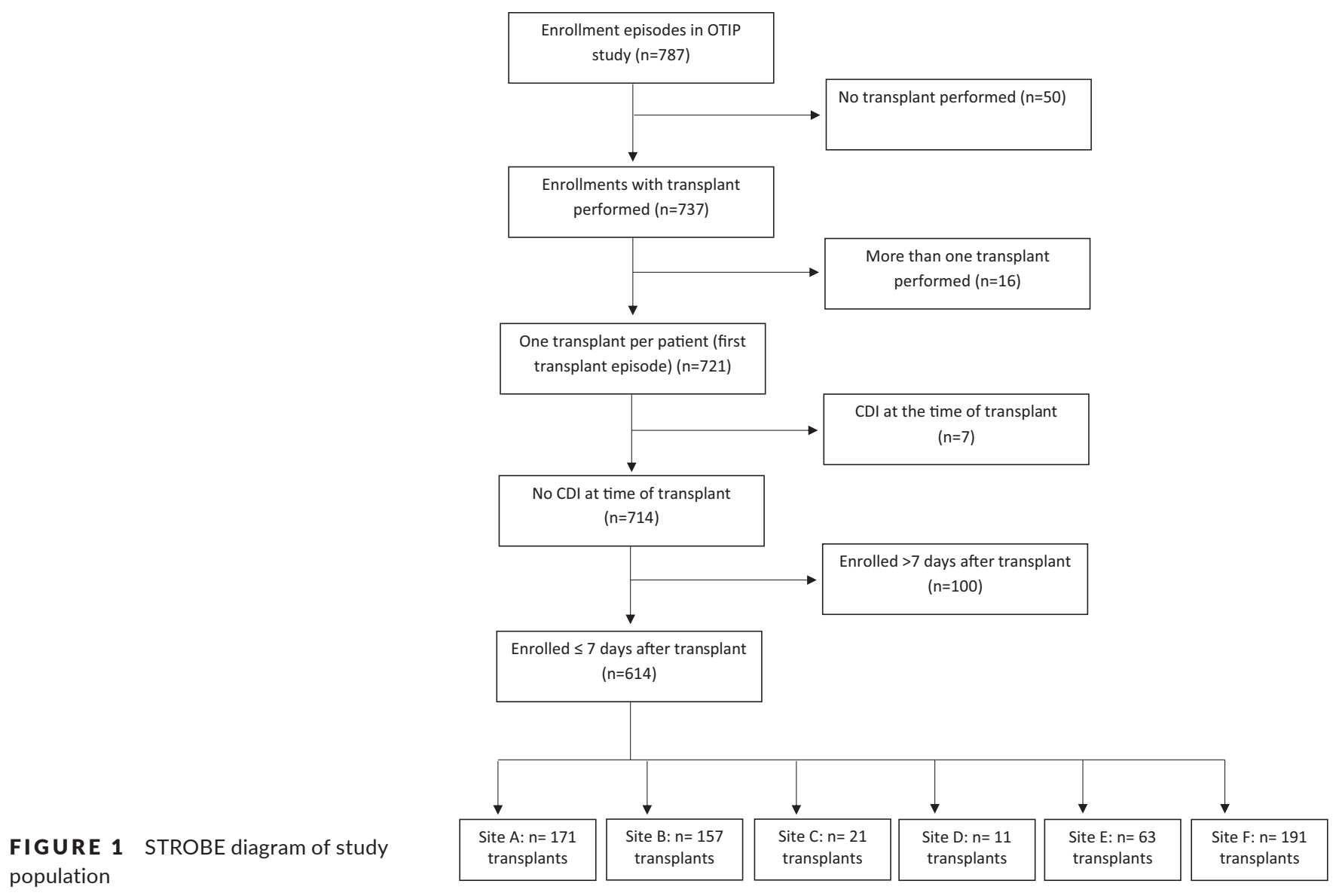

TAB LE 1 Clostridium difficile infections (CDI) in 229 lung transplant recipients

\begin{tabular}{lllll} 
Site & $\begin{array}{l}\text { Enrollment } \\
\mathrm{N}(\%)\end{array}$ & $\begin{array}{l}\text { CDI } \\
\mathrm{N}(\%)\end{array}$ & $\begin{array}{l}\text { CDI rate per 100 lung } \\
\text { transplants }\end{array}$ & $\begin{array}{l}\text { Time to CDI } \\
\text { Median days (range) }\end{array}$ \\
\hline A & $171(75)$ & $22(73)$ & 12.9 & $105(4-331)$ \\
\hline B & $30(13)$ & $7(23)$ & 23.3 & $17(4-282)$ \\
\hline C & $21(9)$ & $1(3)$ & 4.8 & $(116)^{\mathrm{a}}$ \\
\hline D & $2(1)$ & $0(0)$ & 0.0 & - \\
\hline E & $5(2)$ & $0(0)$ & 0.0 & - \\
\hline F & NA & NA & NA & 90 \\
\hline Total & 229 & 30 & 13.1 & - \\
\hline
\end{tabular}

${ }^{\mathrm{a}}$ Median not calculated because of only $1 \mathrm{CDI}$ case patient.

developed CDI within 365 days of transplant: 30 (20\% of CDIs) among lung transplant recipients (incidence 13.1\%) and 120 (80\% of CDIs) among allogeneic HCT recipients (incidence 31.2\%).

Clostridium difficile infection incidence and time to infection in lung transplant recipients is shown in Table 1 and in allogeneic HCTs in Table 2. Site A enrolled $75 \%$ of the lung transplant patients. Two sites did not have any CDI cases; however, these sites accounted for only 7 transplants. Among the 3 sites with CDI cases among lung transplant recipients, site $A$ had a median time to $C D I$ of >100 days post-transplant, and time to the single CDI case at site $C$ was 116 days. Site $B$ had a much shorter median time to CDI onset of 17 days; at site B, 4 of the 7 CDI cases occurred within 20 days of transplant, one occurred at day 90 , and 2 occurred $>100$ days post-transplantation. All 4 sites that enrolled allogeneic HCT patients reported CDI cases, with rates ranging from 12.1 to $37.8 \mathrm{CDI}$ per 100 transplants. The median time from transplant to CDI ranged from 23 to 48 days at the 4 sites. Overall, the median time from transplant to CDI was shorter among allogeneic HCT recipients than among lung transplant recipients (mean $=27$ days vs 90 days; $P=.037$; Figure 2 ). 


\begin{tabular}{lllll} 
Site & $\begin{array}{l}\text { Enrollment } \\
\text { N (\%) }\end{array}$ & $\begin{array}{l}\text { CDI } \\
\text { N (\%) }\end{array}$ & $\begin{array}{l}\text { CDI rate per 100 } \\
\text { allogeneic HCTs }\end{array}$ & $\begin{array}{l}\text { Time to CDI } \\
\text { Median days (range) }\end{array}$ \\
\hline A & NA & NA & NA & NA \\
\hline B & $127(33)$ & $48(40)$ & 37.8 & $48(1-340)$ \\
\hline C & NA & NA & NA & - \\
\hline D & $9(2)$ & $2(2)$ & 22.2 & $(6,50)^{\mathrm{a}}$ \\
\hline E & $58(15)$ & $7(6)$ & 12.1 & $47(1-230)$ \\
\hline F & $191(50)$ & $63(53)$ & 33.0 & $23(1-365)$ \\
\hline Total & 385 & 120 & 31.2 & 27 \\
\hline
\end{tabular}

TABLE 2 Clostridium difficile infections (CDI) in 385 allogeneic hematopoietic cell (HCT) transplant recipients

${ }^{a}$ Median not calculated because of $2 \mathrm{CDI}$ case patients.

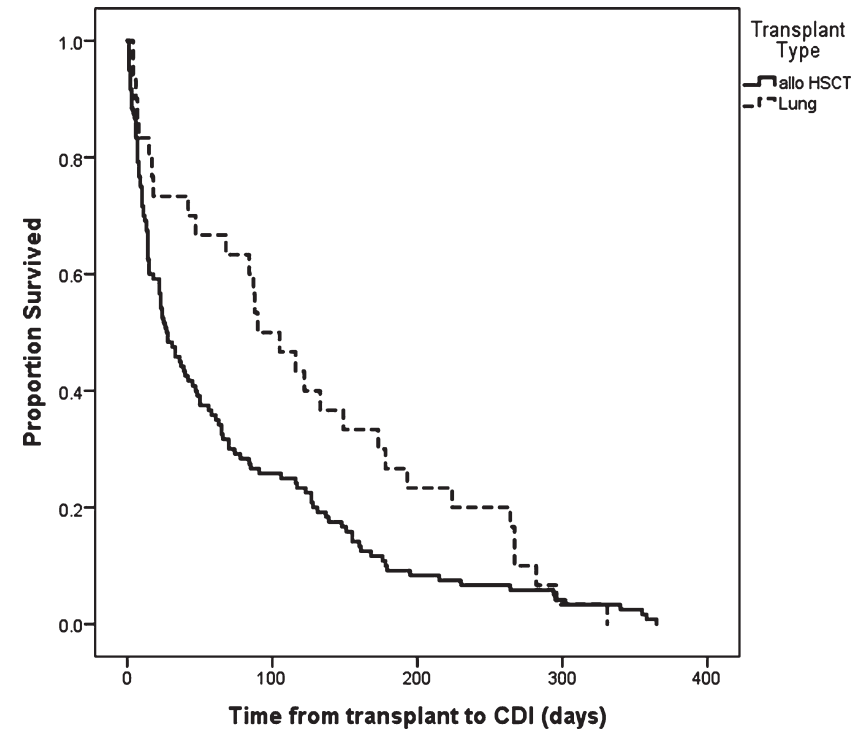

FIGURE 2 Comparison of time from transplant to Clostridium difficile infection (CDI) by transplant type. The median time from transplant to CDI was $27 \mathrm{~d}$ among allogeneic hematopoietic cell transplant patients and $90 \mathrm{~d}$ among lung transplant patients (logrank $P=.037$ )

Patient characteristics associated with CDI after lung transplantation are shown in Table 3 and after allogeneic HCT are shown in Table 4. Among lung transplant recipients only renal failure was significantly associated with $\mathrm{CDI}$, but the numbers were very small. After allogeneic HCT, patients with CDI were more likely than uninfected patients to have received myeloablative conditioning (61\% vs $38 \% ; P=.003$ ) and high dose dexamethasone (20\% vs $13 \% ; P=.053$ ). Other cardiovascular disease was the only comorbidity that was more common among $\mathrm{CDI}$ cases than uninfected $\mathrm{HCT}$ recipients ( $29 \%$ vs $18 \%$; $P=.015$ ), and lack of a preexisting comorbid disease was more common among uninfected persons than CDI cases $(46 \%$ vs $31 \% ; P=.004)$. These relationships were primarily driven by site F, which enrolled $50 \%$ of the allogeneic HCTs. When site F was removed from analyses, those 2 comorbidity variables were no longer statistically significant (data not shown). By contrast, when site $\mathrm{F}$ was excluded, myeloablative conditioning remained associated with CDI: $86 \%$ of cases received myeloablative conditioning vs $68 \%$ of controls $(P=.01)$. Any GVHD in the previous 30 days was more common among $C D I$ cases than controls ( $23 \%$ vs $12 \% ; P=.003$ ). History of a symptomatic urinary tract infection (UTI) in the 30 days before the index date was more common among CDI cases than uninfected persons, although the difference was of borderline significance $(6 \%$ vs $2 \%, P=.06$ ).

Among lung transplant recipients, several outcomes (renal failure, BSI, and pneumonia) occurred significantly more often among CDI cases than controls in the 30 days post-index date $(P<.05$ for all; Table 3). Notably, $27 \%$ of CDI cases experienced a BSI during the 30 days post-index date. Among the allogeneic $\mathrm{HCT}$ recipients, CDI cases were more likely than controls to have any GVHD during the 30 days post-index date ( $40 \%$ vs $27 \%$; $P=.009$; Table 4 ).

Survival within 180 days after $\mathrm{CDI} /$ index date is shown in Figure 3 for lung transplant recipients and Figure 4 for allogeneic $\mathrm{HCT}$ recipients. Among the lung transplants recipients, Cox regression was performed using a heavy-side function to compare mortality in the periods $0-30,31-120$, and 121-180 days post-index date. There was no significant difference in mortality between $C D I$ cases and controls during the early periods $(P=.98$ and $P=.23$ ). There was a trend toward increased mortality during the late period among $C D I$ cases (Hazard ratio [HR] = 4.7 [95\% Cl 0.8-28.1]; $P=.09$ ) compared to controls. Among allogeneic HCT recipients, Cox regression was performed using a heavy-side function to determine mortality in the early time period 0-30 days compared to the later time period 31-180 days post-index date. There was no significant difference in mortality between $\mathrm{CDI}$ cases and controls during the early period $(P=.52)$, but mortality was significantly higher among $C D I$ cases during the late period $(\mathrm{HR}=1.80$ [95\% Cl 1.2-2.8]; $P=.007$ ) compared to controls. Among patients who had died by 180 days post-index date, the underlying disease was the cause of death among $27 \%$ of allogeneic HCT recipients and $8 \%$ of lung transplant recipients $(P=.07)$, and any infection was the cause of death among $21 \%$ of the allogeneic HCT recipients and $32 \%$ of the lung transplant recipients $(P=.21)$.

\section{4 | DISCUSSION}

We compared the epidemiology of CDI in lung transplant and allogeneic HCT recipients. Overall, CDI is common in both populations, 
TABLE 3 Variables associated with Clostridium difficile infection (CDI) after lung transplantation $(\mathrm{N}=229 ; P \leq .20)^{\mathrm{a}}$

\begin{tabular}{|c|c|c|c|c|}
\hline Variable & $\begin{array}{l}\text { CDI } \\
N(\%)\end{array}$ & $\begin{array}{l}\text { No CDI } \\
\mathrm{N}(\%)\end{array}$ & OR $(95 \% \mathrm{Cl})$ & $P$-value \\
\hline \multicolumn{5}{|l|}{ Risk factors } \\
\hline \multicolumn{5}{|l|}{ Comorbidities } \\
\hline $\begin{array}{l}\text { Gastroesophageal reflux } \\
\text { disease }\end{array}$ & $12(40)$ & $52(26)$ & $1.9(0.9-4.2)$ & .12 \\
\hline Other GI disease & $5(17)$ & $15(8)$ & $2.5(0.8-7.3)$ & $.15^{\mathrm{c}}$ \\
\hline \multicolumn{5}{|c|}{ Severity of illness in $30 \mathrm{~d}$ before index date } \\
\hline ICU admission & $11(37)$ & $48(24)$ & $1.8(0.8-4.1)$ & .14 \\
\hline Mechanical ventilation & $11(37)$ & $48(24)$ & $1.8(0.8-4.1)$ & .14 \\
\hline Renal failure & $3(10)$ & $3(2)$ & $7.3(1.4-37.8)$ & $.031^{\mathrm{c}}$ \\
\hline Symptomatic UTI & $2(7)$ & $3(2)$ & $4.7(0.7-29.2)$ & $.13^{\mathrm{c}}$ \\
\hline \multicolumn{5}{|l|}{ Outcomes } \\
\hline ICU admission ${ }^{b}$ & $3(10)$ & $8(4)$ & $2.7(0.7-10.6)$ & $.16^{c}$ \\
\hline Mechanical ventilation & $5(17)$ & $15(8)$ & $2.5(0.8-7.3)$ & $.15^{\mathrm{c}}$ \\
\hline Renal failure & $3(10)$ & $4(2)$ & $5.4(1.2-25.5)$ & $.050^{c}$ \\
\hline BSI & $3(10)$ & $2(1)$ & $10.9(1.7-68.5)$ & $.017^{c}$ \\
\hline Pneumonia & $8(27)$ & $13(7)$ & $5.2(1.9-13.9)$ & $<.001$ \\
\hline Symptomatic UTI & $2(7)$ & $3(2)$ & $4.7(0.7-29.2)$ & $.13^{c}$ \\
\hline
\end{tabular}

aPotential risk factors and outcomes with $P>.20$ not included in the table: Age, sex, race, coronary artery disease, congestive heart failure, peripheral vascular disease, other cardiovascular disease, COPD, asthma, other pulmonary disease, cirrhosis, chronic renal insufficiency, end state renal disease, hemodialysis, peritoneal dialysis, splenectomy, diabetes, autoimmune disease, HIV, HCV, HBV, other comorbid disease, no comorbid disease, all pre-transplant medications; dialysis, bloodstream infection, pneumonia, febrile neutropenia, viremia, or respiratory tract infection in $30 \mathrm{~d}$ before index date; dialysis, viremia, and respiratory tract infection in $30 \mathrm{~d}$ after index date, urinary tract infection (UTI). ${ }^{b}$ ICU admissions at index date are excluded.

${ }^{\text {c}}$ Fisher's exact test. but the incidence among allogeneic HCT recipients is more than 2 times higher than the incidence of $\mathrm{CDI}$ in lung transplant recipients.

The epidemiology of CDI after lung transplantation is unclear, and the varying duration of follow-up periods in previous studies make it difficult to make comparisons among studies. CDI incidence has been estimated in the range of $7 \%-31 \%,{ }^{20}$ and a recent metaanalysis reported the pooled prevalence of $\mathrm{CDI}$ at $10.8 \%$, but the duration of follow-up varied by study. ${ }^{21}$ Lee et al and Dallal et al retrospectively reviewed $\mathrm{CDI}$ in lung transplant recipients and reported incidence estimates of $>20 \%-31 \%$, but their analyses covered $>10$ years. ${ }^{15,16,22}$ Gunderson et $\mathrm{al}^{23}$ reported a lower CDI incidence of $4 \%$ within 1 year of lung transplantation compared with our estimate of $13.1 \%$. It may be that CDI incidence after lung transplantation varies by site as a result of practice variation, such as differing candidate selection, pre-transplant medications, and antimicrobial prophylaxis. Further multicenter studies with detailed analyses of risk factors for $\mathrm{CDI}$ are needed to address these questions.

We found the median time from transplant to CDI was significantly shorter among allogeneic HCT recipients than lung transplant recipients. This is likely due in part to the comparatively greater immunosuppression caused by allogeneic HCT conditioning regimens, with subsequent prolonged neutropenia, mucositis, and intense antimicrobial exposures. Notably, CDI cases among allogeneic HCT recipients were more likely than uninfected recipients to have received myeloablative conditioning or high dose dexamethasone. The relationship between myeloablative conditioning and CDI in HCT recipients has been noted previously. ${ }^{7,11}$ The underlying biological mechanism behind this relationship may be 2 -fold: myeloablative conditioning increases neutropenia, damages the gut mucosa, and is associated with a higher risk of infection in the pre-engraftment period (and thus exposure to broad spectrum antimicrobials) vs non-ablative conditions; all of these may increase risk of CDI. ${ }^{24}$ Alternatively, patients who receive myeloablative conditioning are more likely to develop diarrhea, and thus more likely to have concurrent asymptomatic $C$. difficile colonization detected. Notably, approximately half of the $\mathrm{CDI}$ cases in this study occurred $>30$ days after transplant, suggesting heightened suspicion of CDI after allogeneic HCT should continue beyond the immediate post-transplant period.

By comparison, $\mathrm{CDI}$ among lung transplant recipients appeared to occur more often in the later post-transplant period. The median time to $\mathrm{CDI}$ after lung transplant was 90 days, although this estimate was primarily driven by the $22 \mathrm{CDI}$ cases at site $\mathrm{A}$. Site $\mathrm{B}$, which reported $7 \mathrm{CDI}$ cases, had a median time to $\mathrm{CDI}$ of only 17 days. The time to CDI at site $B$ appeared bi-modal, with 4 cases within 30 days of transplant and 3 cases from day 90 or later. This bi-modal 


\begin{tabular}{|c|c|c|c|c|}
\hline Variable & $\begin{array}{l}\text { CDI } \\
\mathrm{N}(\%)\end{array}$ & $\begin{array}{l}\text { No CDI } \\
N(\%)\end{array}$ & OR $(95 \% \mathrm{Cl})$ & $P$-value \\
\hline \multicolumn{5}{|l|}{ Risk factors } \\
\hline \multicolumn{5}{|l|}{ Comorbidities } \\
\hline $\begin{array}{l}\text { Other cardiovascular } \\
\text { disease }\end{array}$ & $35(29)$ & $48(18)$ & $1.9(1.1-3.1)$ & .015 \\
\hline $\begin{array}{l}\text { Diabetes not requiring } \\
\text { insulin }\end{array}$ & $9(8)$ & $8(3)$ & $2.6(1.0-6.9)$ & .047 \\
\hline No comorbid disease & $37(31)$ & $123(46)$ & $0.5(0.3-0.8)$ & .004 \\
\hline \multicolumn{5}{|l|}{ Pre-transplant medications } \\
\hline $\begin{array}{l}\text { Dexamethasone (high } \\
\text { dose) }\end{array}$ & $24(20)$ & $33(13)$ & $1.8(1.0-3.1)$ & .053 \\
\hline ATGAM & $7(6)$ & $26(10)$ & $0.6(0.2-1.4)$ & .20 \\
\hline Other immunomodulator & $32(27)$ & $53(20)$ & $1.5(0.9-2.4)$ & .14 \\
\hline Fludarabine & $41(34)$ & $115(43)$ & $0.7(0.4-1.1)$ & .09 \\
\hline Busulfan & $67(56)$ & $171(65)$ & $0.7(0.4-1.1)$ & .10 \\
\hline Campath & $0(0)$ & $7(3)$ & Undef & $.10^{\mathrm{b}}$ \\
\hline $\begin{array}{c}\text { Myeloablative } \\
\text { conditioning }\end{array}$ & $33(61)$ & $55(38)$ & $2.6(1.4-4.9)$ & .003 \\
\hline \multicolumn{5}{|c|}{ Severity of illness in $30 \mathrm{~d}$ before index date } \\
\hline Symptomatic UTI & $7(6)$ & $5(2)$ & $3.2(1.0-10.4)$ & $.055^{\mathrm{b}}$ \\
\hline $\begin{array}{l}\text { Graft versus host disease } \\
\text { (any) }\end{array}$ & $28(23)$ & $31(12)$ & $2.3(1.3-4.0)$ & .003 \\
\hline \multicolumn{5}{|l|}{ Outcomes } \\
\hline Pneumonia & $7(6)$ & $8(3)$ & $2.0(0.7-5.6)$ & .19 \\
\hline Viremia & $14(12)$ & $16(6)$ & $2.1(1.0-4.4)$ & .056 \\
\hline Respiratory tract infection & $0(0)$ & $7(3)$ & Undef & $.10^{\mathrm{b}}$ \\
\hline $\begin{array}{l}\text { Graft versus host disease } \\
\text { (any) }\end{array}$ & $48(40)$ & $71(27)$ & $1.8(1.2-2.9)$ & .009 \\
\hline
\end{tabular}

TAB LE 4 Variables associated with Clostridium difficile infection (CDI) after allogeneic hematopoietic cell transplant $(\mathrm{HCT})(\mathrm{N}=385 ; \mathrm{P} \leq .20)^{\mathrm{a}}$

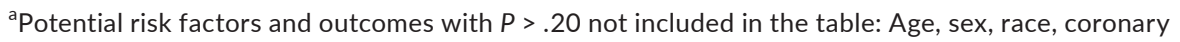
artery disease, congestive heart failure, peripheral vascular disease, COPD, asthma, other pulmonary disease, GERD, cirrhosis, other GI disease, chronic renal insufficiency, end stage renal disease, hemodialysis, peritoneal dialysis, splenectomy, diabetes requiring insulin, autoimmune disease, HIV, HCV, HBV, other disease, unmatched HCT donor, unrelated HCT donor, status of malignancy; other pre-transplant medications, ICU admission, mechanical ventilation, renal failure, dialysis, bloodstream infection, pneumonia, febrile neutropenia, viremia, or respiratory tract infection in $30 \mathrm{~d}$ before index date; ICU admission, mechanical ventilation, renal failure, dialysis, bloodstream infection, symptomatic urinary tract infection (UTI), febrile neutropenia, or respiratory tract infection in $30 \mathrm{~d}$ after index date.

${ }^{\mathrm{b}}$ Fisher's exact test.

distribution was not evident at site A. This discrepancy may be caused by different transplant characteristics at the 2 sites or the small sample size at site B. Conversely, it is possible that the lung transplant recipients do have 2 distinct phases of increased risk for CDI: the first immediately following transplantation, and the second in the later post-transplant period, resulting from increased or renewed exposure to $C D I$ risk factors.

Although antimicrobial usage data were not available for these analyses, we did have prospectively collected data on other infections among the transplant recipients, which can be used as a surrogate marker for antimicrobial use. ${ }^{25}$ Additionally, transplant recipients, particularly allogeneic HCT, have almost universal exposure to antimicrobials. Among the allogeneic HCT recipients, symptomatic UTI was a borderline risk factor for CDI. UTIs are often treated with antimicrobials such as fluoroquinolones or cephalosporins, which in turn may increase the risk of CDI. An analysis using Medicare data found that UTIs were responsible for a greater population attributable risk fraction of CDI cases than any other type of infection, ${ }^{25}$ and they may be a useful antimicrobial stewardship target.

We found mortality within 180 days of CDI/index date to be significantly higher in the allogeneic HCT population but not the lung transplant population. CDI was not associated with increased risk of mortality within the first 30 days, but mortality was 


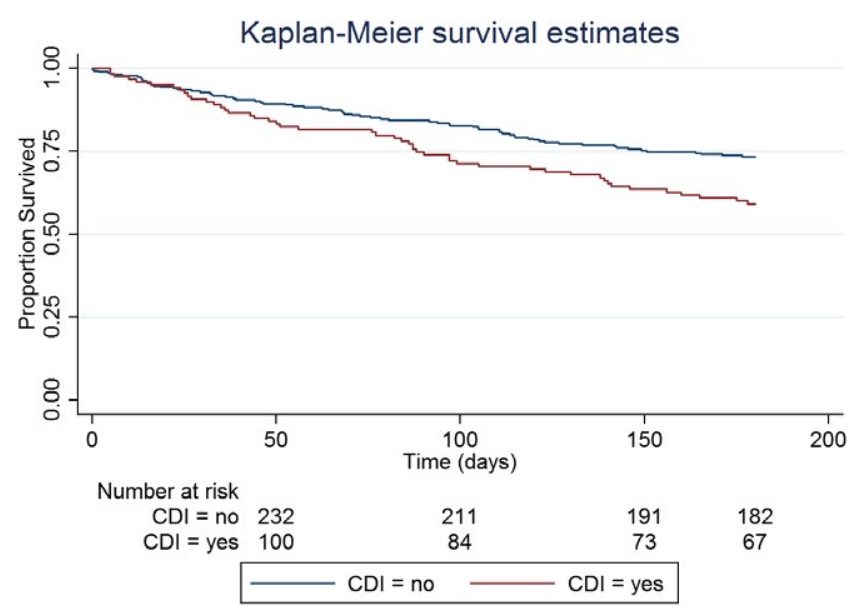

FIGURE 3 Lung transplant recipients: Survival at $180 \mathrm{~d}$ after index date, stratified by Clostridium difficile infection (CDI) status

significantly higher among CDI cases from 31 to 180 days postindex date after allogeneic HCT. This finding is different from that of Willems et al, ${ }^{14}$ who found no significant difference in survival between CDI cases and controls within 2 years. Willems et al measured survival post-HCT, whereas we measured survival in days from $C D I$ or a random index date, selected to match the distribution of CDI case onset in the post-HCT period. Among the lung transplant recipients, while we did not detect a significant difference in survival at 180 days post-CDI/index date, we did find that mortality was marginally higher among CDI cases from 120 to 180 days post-index date. Lee et $\mathrm{al}^{16}$ found mortality among lung transplant recipients to be significantly higher after $\mathrm{CDI}$, but their retrospective single-center cohort spanned 11 years. It may be necessary to follow lung transplant recipients for a longer period of time to detect the effect of CDI on mortality. Notably, we found BSI and pneumonia to be significantly more frequent in the 30 days after $\mathrm{CDI}$ in the lung transplant population. It is unclear whether these infections truly result from CDI (or increased healthcare exposure caused by $C D I$ ), or whether CDI is merely a marker of increasing severity of illness. Alternatively, these infections may be a result of microbiome disruption associated with $\mathrm{CDI}$; this relationship has been suggested previously with $\mathrm{CDI}$ and sepsis. ${ }^{26}$ Overall, our data suggest that CDI likely increases mortality in allogeneic HCT recipients, while more data are needed on CDI and mortality after lung transplantation.

There are several limitations to this study. Because OTIP's original focus was on fungal infections, not CDI, data on antimicrobials were not collected. Stool samples were not collected, so we were unable to evaluate colonization with $C$. difficile. A variety of $C$. difficile diagnostic tests were used at the participating sites, and these may affect $\mathrm{CDI}$ rates. ${ }^{27}$ Additionally, CDI epidemiology and C. difficile diagnosis have continued to change since this study was performed; for example, use of molecular diagnostics has increased. ${ }^{27}$ Finally, this study was not designed for a detailed analysis of the relationship between CDI and GVHD. This relationship is complex, and previous research suggests GVHD, which is associated with loss of

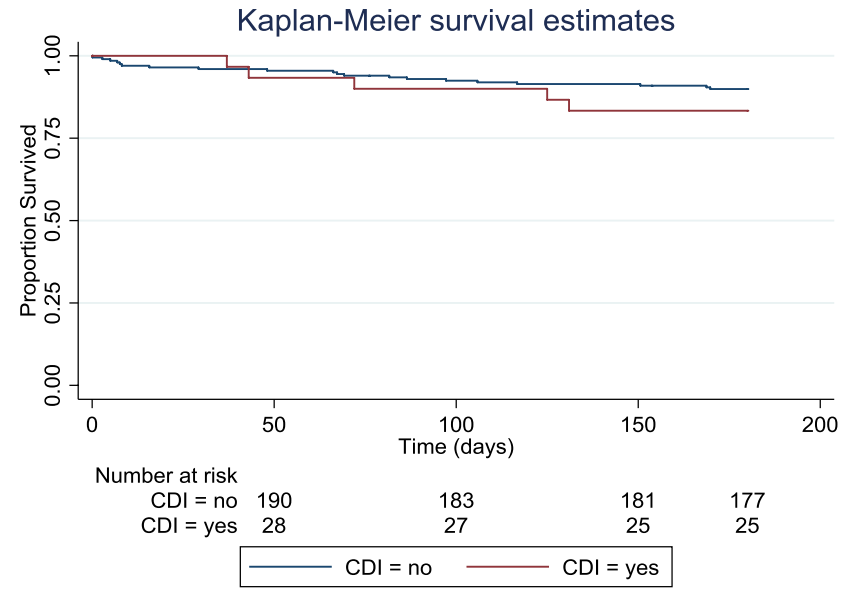

FIGURE 4 Allogeneic hematopoietic cell transplant recipients: Survival at $180 \mathrm{~d}$ after index date, stratified by Clostridium difficile infection (CDI) status

a healthy gut microbiome, may be both a risk factor and outcome of CDI. $6,7,24,28-30$ This deserves additional study. Despite these limitations, this analysis has several strengths, including a prospective, multicenter, cohort study design. Patient assessments were performed throughout the study, regardless of whether the participants were inpatients or outpatients. The data collected were not limited to medical records and/or inpatient hospitalizations, and thus more accurately reflect patients' clinical status throughout the posttransplant period.

While no consensus exists on the exact burden among immunocompromised patients, CDI is clearly a problematic infection; the current analysis provides useful data on the epidemiology and outcomes of CDI in allogeneic HCT and lung transplant recipients. The epidemiology of CDI varies by transplant population, with CDI generally occurring earlier post-transplant among allogeneic $\mathrm{HCT}$ recipients than lung transplant recipients. Variations in CDI incidence among the 6 sites participating in the OTIP study suggest local practices may influence risk and outcomes of CDI; this is an important area for future study. CDI may be both a cause and indicator of increasing morbidity, particularly among lung transplant recipients. Innovative strategies for CDI prevention and treatment among allogeneic HCT and lung transplant recipients are needed.

\section{ACKNOWLEDGEMENTS}

Funding: This work was supported by the Organ Transplant Infection Detection and Prevention Program (OTIP) of the Centers for Disease Control and Prevention (U01CK000134). This work was also funded by a grant from the National Institutes for Health (K23A1065806).

Disclosure: E.R.D. has received research support from Sanofi Pasteur, Merck, and Rebiotix, and has been a consultant for Sanofi Pasteur, Merck, Rebiotix, Summit, Valneva, and Pfizer, all unrelated to this study. M.A.O. has received research support from Pfizer and 
Sanofi Pasteur and has been a consultant for Pfizer, all unrelated to this study. R.K.A. has received research support from Shire, Astellas, Merck, Chimerix, and Oxford Immunotec, all unrelated to this study. K.A.R., K.B., A.A.C., F.P.S., M.G.S., C.A.K, P.G.P., and T.M.C. have no conflicts of interest to disclose.

\section{AUTHOR CONTRIBUTIONS}

ERD: Secured funding; Concept/design, Data analysis/interpretation, Drafting manuscript; Critical revision of article; KAR: Data collection/management; Data analysis/interpretation, Drafting manuscript; Critical revision of article; MAO: Data analysis/ interpretation, Drafting manuscript; Critical revision of article; KB: Data collection/management; Critical revision of article; AAC: Data collection/management; Critical revision of article; FPS: Secured funding; Concept/design; Critical revision of article; MGS: Secured funding; Concept/design; Critical revision of article; CAK: Secured funding; Concept/design; Critical revision of article; RKA: Secured funding; Concept/design; Critical revision of article; PGP: Secured funding; Concept/design; Critical revision of article; TMC: Concept/design; Critical revision of article.

\section{ORCID}

E.R. Dubberke (iD http://orcid.org/0000-0003-3779-2796

K.A. Reske (iD http://orcid.org/0000-0003-4752-8796

R.K. Avery (iD http://orcid.org/0000-0001-7692-3619

\section{REFERENCES}

1. Bignardi GE. Risk factors for Clostridium difficile infection. J Hosp Infect. 1998;40:1-15.

2. Kyne L, Sougioultzis S, McFarland LV, Kelly CF. Underlying disease severity as a major risk factor for nosocomial Clostridium difficile diarrhea. Infect Control Hosp Epidemiol. 2002;23:653-659.

3. Loo VG, Bourgault AM, Poirier L, et al. Host and pathogen factors for Clostridium difficile infection and colonization. N Engl J Med. 2011;365:1693-1703.

4. McFarland LV, Surawicz CM, Stamm WE. Risk factors for Clostridium difficile carriage and $\mathrm{C}$. difficile-associated diarrhea in a cohort of hospitalized patients. J Infect Dis. 1990;162:678-684.

5. Honda H, Dubberke ER. Clostridium difficile infection in solid organ transplant recipients. Curr Opin Infect Dis. 2014;27:336-341.

6. Alonso CD, Treadway SB, Hanna DB, et al. Epidemiology and outcomes of Clostridium difficile infections in hematopoietic stem cell transplant recipients. Clin Infect Dis. 2012;54:1053-1063.

7. Boyle NM, Magaret A, Stednick Z, et al. Evaluating risk factors for Clostridium difficile infection in adult and pediatric hematopoietic cell transplant recipients. Antimicrob Resist Infect Control. 2015;4:41.

8. Chakrabarti S, Lees A, Jones SG, Milligan DW. Clostridium difficile infection in allogeneic stem cell transplant recipients is associated with severe graft-versus-host disease and non-relapse mortality. Bone Marrow Transplant. 2000;26:871-876.

9. Chopra T, Chandrasekar P, Salimnia H, Heilbrun LK, Smith D, Alangaden GJ. Recent epidemiology of Clostridium difficile infection during hematopoietic stem cell transplantation. Clin Transplant. 2011:25:E82-E87.
10. Kamboj M, Xiao K, Kaltsas A, et al. Clostridium difficile infection after allogeneic hematopoietic stem cell transplant: strain diversity and outcomes associated with NAP1/027. Biol Blood Marrow Transplant. 2014;20:1626-1633.

11. Kinnebrew MA, Lee YJ, Jenq RR, et al. Early Clostridium difficile infection during allogeneic hematopoietic stem cell transplantation. PLoS One. 2014;9:e90158.

12. Leung S, Metzger BS, Currie BP. Incidence of Clostridium difficile infection in patients with acute leukemia and lymphoma after allogeneic hematopoietic stem cell transplantation. Infect Control Hosp Epidemiol. 2010;31:313-315.

13. Mani S, Rybicki L, Jagadeesh D, Mossad SB. Risk factors for recurrent Clostridium difficile infection in allogeneic hematopoietic cell transplant recipients. Bone Marrow Transplant. 2016;51:713-717.

14. Willems L, Porcher R, Lafaurie M, et al. Clostridium difficile infection after allogeneic hematopoietic stem cell transplantation: incidence, risk factors, and outcome. Biol Blood Marrow Transplant. 2012;18:1295-1301.

15. Dallal RM, Harbrecht BG, Boujoukas AJ, et al. Fulminant Clostridium difficile: an underappreciated and increasing cause of death and complications. Ann Surg. 2002;235:363-372.

16. Lee JT, Kelly RF, Hertz MI, Dunitz JM, Shumway SJ. Clostridium difficile infection increases mortality risk in lung transplant recipients. $J$ Heart Lung Transplant. 2013;32:1020-1026.

17. Pant C, Anderson MP, O'Connor JA, Marshall CM, Deshpande A, Sferra TJ. Association of Clostridium difficile infection with outcomes of hospitalized solid organ transplant recipients: results from the 2009 Nationwide Inpatient Sample database. Transpl Infect Dis. 2012;14:540-547.

18. Dubberke ER, Reske KA, Srivastava A, et al. Clostridium difficileassociated disease in allogeneic hematopoietic stem-cell transplant recipients: risk associations, protective associations, and outcomes. Clin Transplant. 2010;24:192-198.

19. Garner JS, Jarvis WR, Emori TG, Horan TC, Hughes JM. CDC definitions for nosocomial infections, 1988. Am J Infect Control. 1988;16:128-140.

20. Riddle DJ, Dubberke ER. Clostridium difficile infection in solid organ transplant recipients. Curr Opin Organ Transplant. 2008;13: 592-600.

21. Paudel S, Zacharioudakis IM, Zervou FN, Ziakas PD, Mylonakis E. Prevalence of Clostridium difficile infection among solid organ transplant recipients: a meta-analysis of published studies. PLoS One. 2015;10:e0124483.

22. Lee JT, Hertz MI, Dunitz JM, et al. The rise of Clostridium difficile infection in lung transplant recipients in the modern era. Clin Transplant. 2013;27:303-310.

23. Gunderson CC, Gupta MR, Lopez F, et al. Clostridium difficile colitis in lung transplantation. Transpl Infect Dis. 2008;10: 245-251.

24. Docampo MD, Auletta JJ, Jenq RR. Emerging influence of the intestinal microbiota during allogeneic hematopoietic cell transplantation: control the gut and the body will follow. Biol Blood Marrow Transplant. 2015;21:1360-1366.

25. Dubberke ER, Olsen MA, Stwalley $D$, et al. Identification of Medicare recipients at highest risk for Clostridium difficile infection in the US by population attributable risk analysis. PLoS One. 2016;11:e0146822.

26. Prescott HC, Dickson RP, Rogers MA, Langa KM, Iwashyna TJ. Hospitalization type and subsequent severe sepsis. Am J Respir Crit Care Med. 2015;192:581-588.

27. Burnham CA, Carroll KC. Diagnosis of Clostridium difficile infection: an ongoing conundrum for clinicians and for clinical laboratories. Clinical Microbiol Rev. 2013;26:604-630.

28. Dubberke ER, Reske KA, Olsen MA, et al. Risk for Clostridium difficile infection after allogeneic hematopoietic cell transplant 
remains elevated in the postengraftment period. Transplant Direct. 2017;3:e145.

29. Jenq RR, Ubeda C, Taur Y, et al. Regulation of intestinal inflammation by microbiota following allogeneic bone marrow transplantation. J Exp Med. 2012;209:903-911.

30. Taur $\mathrm{Y}$, Jenq RR, Perales MA, et al. The effects of intestinal tract bacterial diversity on mortality following allogeneic hematopoietic stem cell transplantation. Blood. 2014;124:1174-1182.
How to cite this article: Dubberke ER, Reske KA, Olsen MA, et al. Epidemiology and outcomes of Clostridium difficile infection in allogeneic hematopoietic cell and lung transplant recipients. Transpl Infect Dis. 2018;20:e12855. https://doi. org/10.1111/tid.12855 